\title{
Correction to: Letter regarding, "Association between the use of aspirin and risk of lung cancer: results from pooled cohorts and Mendelian randomization analyses"
}

\author{
Aayah Nounu $^{1}\left[\right.$ Denexia Walker ${ }^{1} \cdot$ Rebecca C. Richmond ${ }^{1}$
}

Published online: 11 April 2021

๑) Springer-Verlag GmbH Germany, part of Springer Nature 2021

\section{Correction to: \\ Journal of Cancer Research and Clinical Oncology https://doi.org/10.1007/s00432-020-03508-z}

The article "Letter regarding, "Association between the use of aspirin and risk of lung cancer: results from pooled cohorts and Mendelian randomization analyses"', written by Aayah Nounu, Venexia Walker and Rebecca C. Richmond, was originally published electronically on the publisher's internet portal on January 12, 2021 with Open Access under a Creative Commons Attribution 4.0 International License.

With the author's decision to cancel Open Access the copyright of the article changed on March 31, 2021 to (C) The Author(s), under exclusive licence to Springer-Verlag
GmbH, DE part of Springer Nature 2021 with all rights reserved.

The original article has been corrected.

Publisher's Note Springer Nature remains neutral with regard to jurisdictional claims in published maps and institutional affiliations.

The original article can be found online at https://doi.org/10.1007/ s00432-020-03508-z.

Aayah Nounu

an0435@bristol.ac.uk

1 Medical Research Council (MRC) Integrative Epidemiology

Unit, Bristol Medical School, University of Bristol,

Bristol BS8 2BN, UK 